\title{
Research Progress and Trend of Plasma Metallurgy on Titanium Metallic Surface
}

\author{
Li Zhengxian ${ }^{1,2,{ }^{*}}$, Zhao Wen ${ }^{1}$, Ji Shouchang ${ }^{1}$, Xu Zhong ${ }^{2}$, Zhou Lian ${ }^{1}$ \\ 1. Northwest Institute of Nonferrous Metal Research, Xi'an, Shaanxi, China \\ 2. Taiyuan University of Technology, Taiyuan, Shanxi, China \\ *Izxqy725@163.com
}

\begin{abstract}
By using vacuum plasma surface metallurgy technology, Chinese scientists have carried out comprehensive research on improving the wear resistance, corrosion resistance and flame retardancy of titanium metal. In this paper, the latest research results of alloy layer formation on titanium surface by plasma metallurgy technology and the development trend of plasma metallurgy technology on titanium surface are summarized.
\end{abstract}

\section{Introduction}

Titanium, although possesses some decent properties of low density, high specific strength and good corrosion resistance, has some major drawbacks, like poor wear resistance, poor high temperature oxidation resistance, flammability and high manufacturing cost. Surface modification of titanium is adopted to overcome those drawbacks and improve their properties. At present, surface modification technologies such as physical vapor deposition, laser cladding, ion implantation, ion nitriding, thermal spraying and micro-arc oxidation have been successfully applied to titanium alloys. Plasma metallurgy on titanium surface is a new kind of surface technology, upon which a lot of research work has been done by many Chinese scholars and researchers, and some important research results have been achieved ${ }^{[1-2]}$.

\section{Double glow plasma surface metallurgy technology}

Double glow plasma surface metallurgy, a major breakthrough based on the "ion ntriding technology" invented by B. Berghaus in 1930, was invented by Professor Xu Zhong of Taiyuan University of Technology in 1980 to realize metalizing elements on the surface of metal materials. This technology has obtained patents form the United States, Great Britain, Canada and many other countries. It uses metal ions provided by plasma, which is generated by double glow discharge in vacuum chamber. Under the action of thermal diffusion and ion bombardment, a layer of coating is formed on the surface of workpiece. Its working principle and experimental setup are shown in Figure ${ }^{[2]}$.

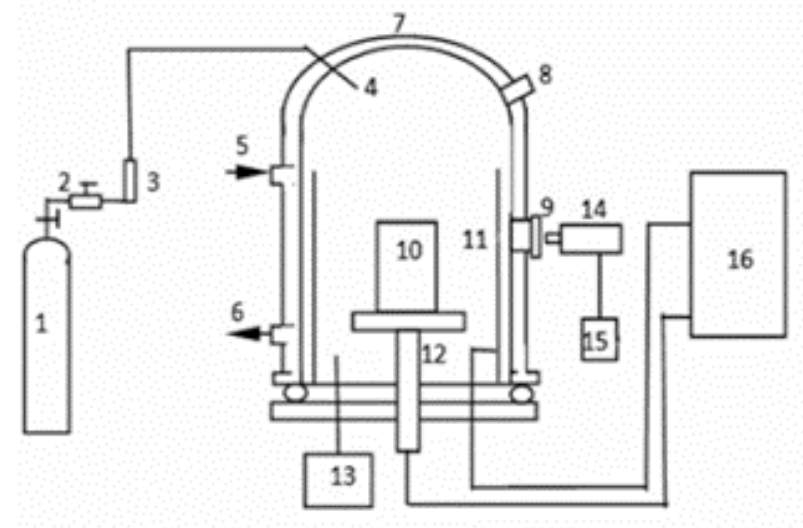

1 cylinders

2 needle valve

3 rotameter

4 intake pipe

5 cooling water inlet

6 cooling water outlet hole

7 vacuum cover

8 peephole

9 observation window

10 work-piece

11 anode

12 cathode plate

13 vacuum pump

14 photoelectric thermometer

15 thermometer

$16 \mathrm{DC}$ power supply

(C) The Authors, published by EDP Sciences. This is an open access article distributed under the terms of the Creative Commons Attribution License 4.0 (http://creativecommons.org/licenses/by/4.0/). 
Figure 1. Schematic diagram of Double glow plasma surface metallurgy experimental setup

The characteristics of double glow plasma surface metallurgy technology are: (1) can be applied to infiltrate one or several kinds of elements into the surface of metal material; (2) precise control of surface alloying process can be achieved by controlling discharge characteristics; (3) plasma generated by double glow and hollow cathode can diffuse rapidly; (4) treatment, conducted in vacuum atmosphere, is environmental friendly.

\section{Research progress of plasma metallurgy on titanium surface}

\subsection{Surface flame retardant titanium alloy}

There is a fatal problem of sustained combustion sensitivity in titanium alloy, which could lead to the failure of "titanium fire". Alloy C (Ti-35V-15Cr), Ti-45Nb, BTT-1 (Ti-13Cu-4Al-4Mo-2Zr) and BTT-3 (Ti-18Cu-2Al-2Mo) alloys are studied by PrattWhitney, ATI Wah Chang, and a Russian company respectively in order to improve the flame retardancy of titanium alloys ${ }^{\text {[3]. }}$

\subsubsection{Plasma metallurgy Ti-Cu flame retardant alloy ${ }^{[4-6]}$}

Figure 2 shows the Ti-Cu alloy layer formed by plasma Cu diffusion on Ti6Al4V substrate. Cu element shows a gradient distribution in surface alloy layer. The weight percentage of $\mathrm{Cu}$ in the outer surface is $14 \%$. At the place $160 \mu \mathrm{m}$ from the surface, it remains at $12 \%$, and the contents of other components are similar to those of Russian BTT-1 alloy. The content of Cu changes continuously from the surface to the substrate, which gradually decreases along the depth with no mutation point, and the average thickness of the modified layer is over $200 \mu \mathrm{m}$.

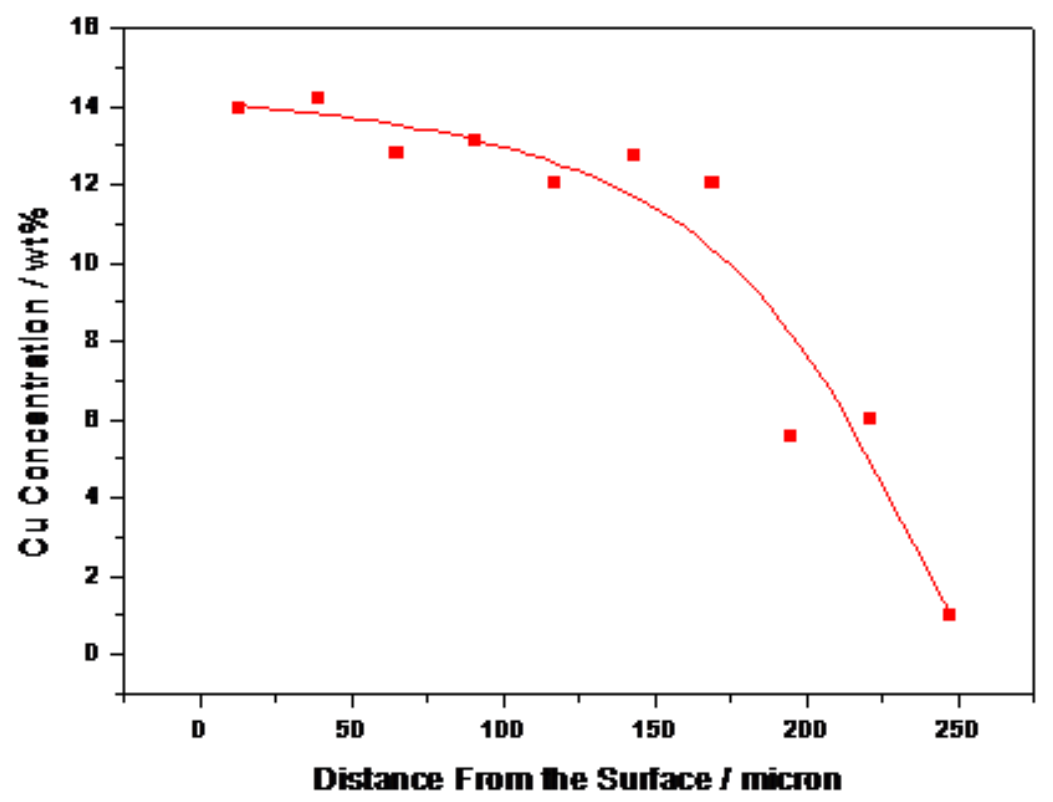

Figure 2. Concentration distribution of $\mathrm{Cu}$ in $\mathrm{Cu}$ alloy layer on Ti6Al4V substrate

The study found that the substrate is still $\alpha+\beta$ phase after plasma diffusion, the alloying layer consists of $\alpha+\beta$ phase and dispersively distributed Ti2 Cu intermetallic compounds. The melting point of $\mathrm{Ti} 2 \mathrm{Cu}$ is $990^{\circ} \mathrm{C}$, means it will soften or melt before combustion, which is helpful to the flame retardant property.

Figure 3 shows the test results for Cu alloy layer formed on the surface of TC11 titanium alloy. Cu element content in the surface alloy layer maintains an approximate constant value of $20 \%$, while that of external surface is relatively low, about $1 \%$. This result is not exactly the same as that of forming Ti-Cu alloy layer on Ti6Al4V substrate by plasma alloying. In order to make the alloy layer on the surface of TC11 has flame retardant properties, $\mathrm{Cu}$ content of surface layer needs to reach $13 \%$ or more. Therefore, surface processing of TC11 surface after plasma Cu diffusion is considered. 


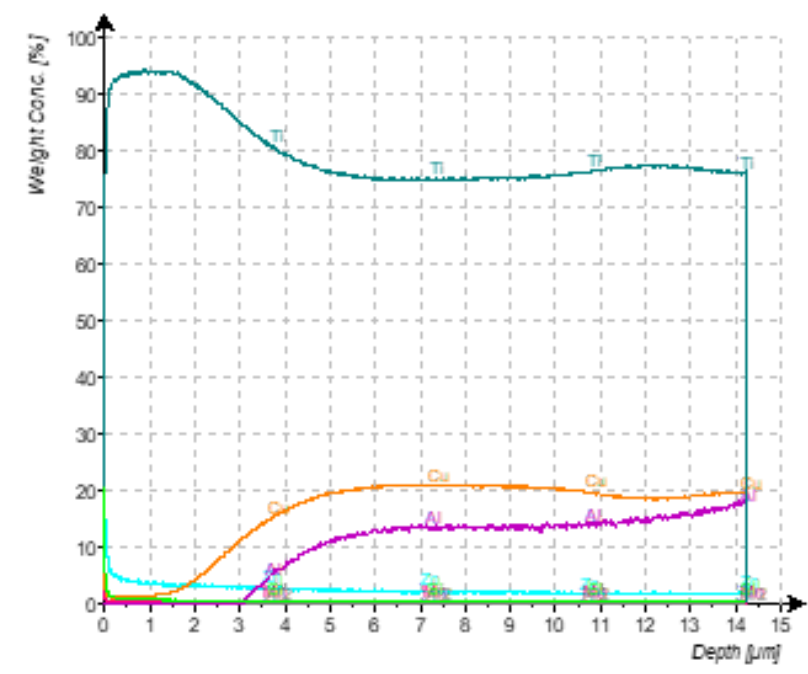

Figure 3. The distribution of Cu in alloy layer on TC11

\subsubsection{Plasma metallurgy Ti-Cr flame retardant alloy [7]}

The content distribution of Ti-Cr alloy layer on TC4 substrate is shown in Figure 4. It can be seen that the content of $\mathrm{Cr}$ is $75 \%$ on the outmost surface. At a distance of $70 \mu \mathrm{m}$ from the surface, it remains above $20 \%$. It fully meets the requirement. The composition distribution of diffusion layer on TC11 titanium alloy after double glow $\mathrm{Cr}$ diffusion is shown in Figure 5 . The content of $\mathrm{Cr}$ is $100 \%$ on the outmost surface. The thickness of the layer is $45 \mu \mathrm{m}$.

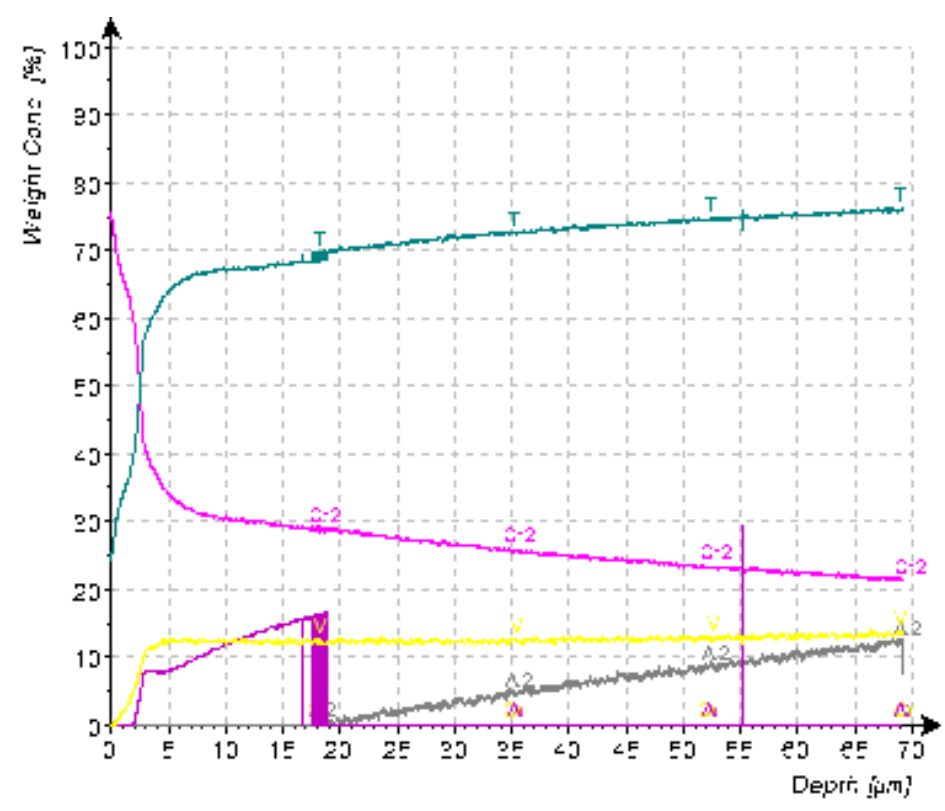

Figure 4. The distribution of $\mathrm{Cr}$ in alloy layer on TC4 


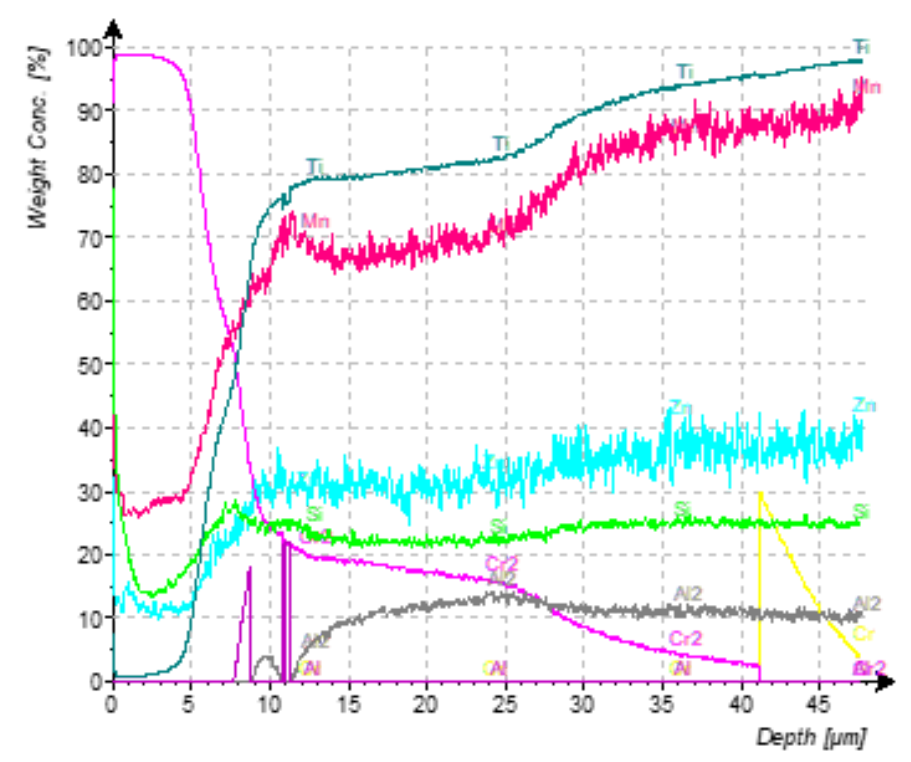

Figure 5. The distribution of $\mathrm{Cr}$ in alloy layer on TC11

The layer structure (Figure 6) of TC11 titanium after double glow $\mathrm{Cr}$ diffusion is intermetallic compound consists of $\alpha, \beta$ Ti and a small amount of dispersively distributed $\mathrm{Cr} 2 \mathrm{Ti}$ (Figure 7). Most of $\mathrm{Cr}$ elements are dissolved in $\beta$ phase.

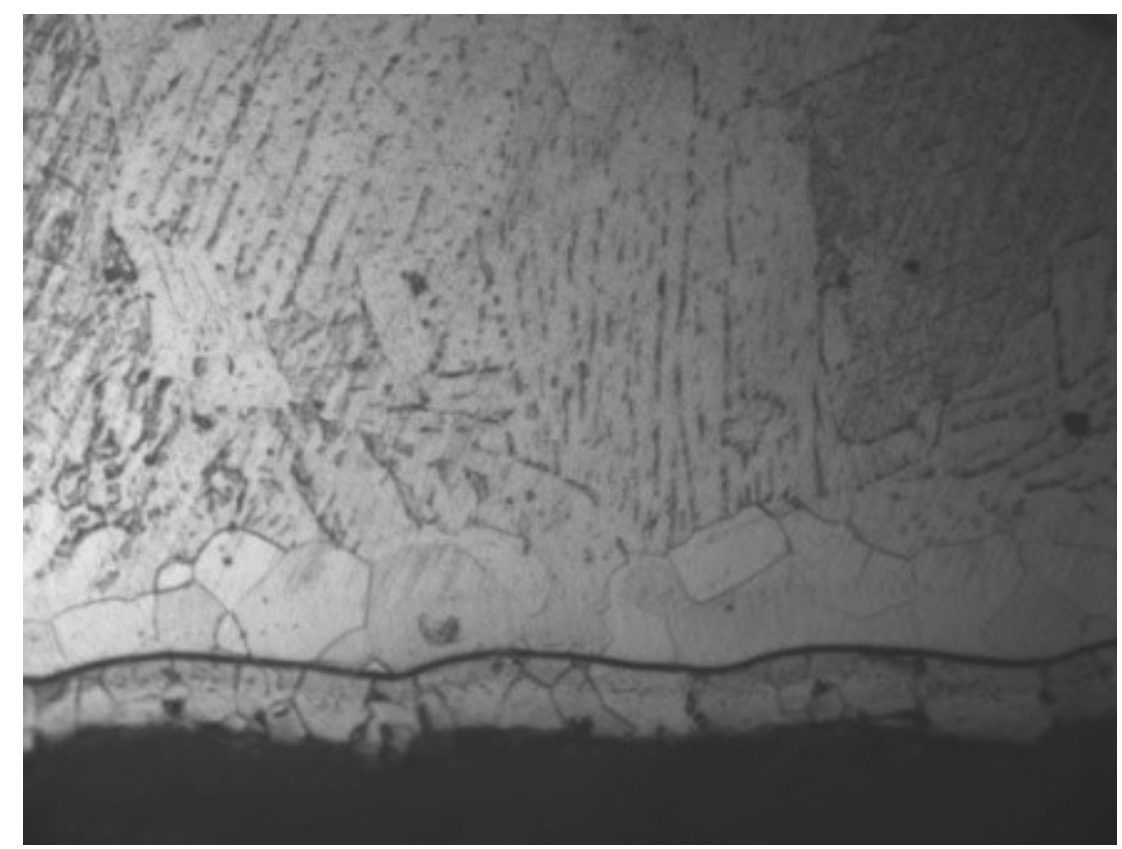

Figure 6. The sectional microstructure of alloy layer after $\mathrm{Cr}$ diffusion on TC11

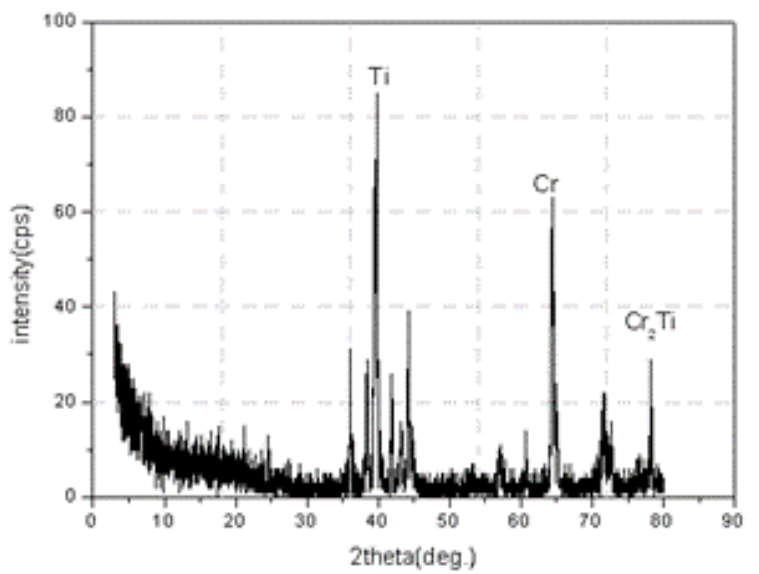


Figure 7. The XRD spectrum of layer after Cr diffusion on TC11

\subsubsection{Other plasma metallurgy flame retardant alloys [8, 9]}

The concentration distribution of alloying elements along the depth of the Nb modified layer in TC4 is shown in Figure 8 . Nb element exhibits a gradient distribution in alloy layer, and the weight percentage in the surface can reach more than $65 \%$. Figure 9 shows the SEM photos of section of alloy layer on TC4. A high alloy layer (white bright layer) of several microns exists on the external surface of the layer. The diffusion layer is mainly composed of $\mathrm{Nb}$ solid solution formed in $\alpha-\mathrm{Ti}$ and $\beta$-Ti.

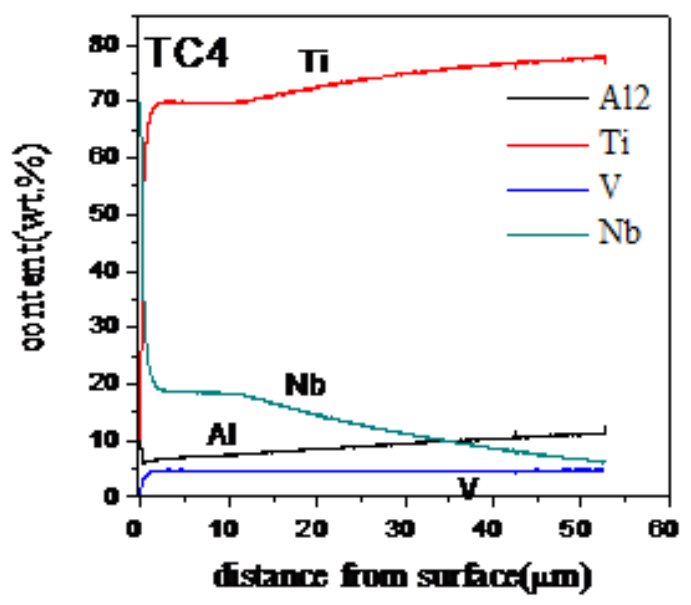

Figure 8. The element distribution curves of alloy layers on TC4

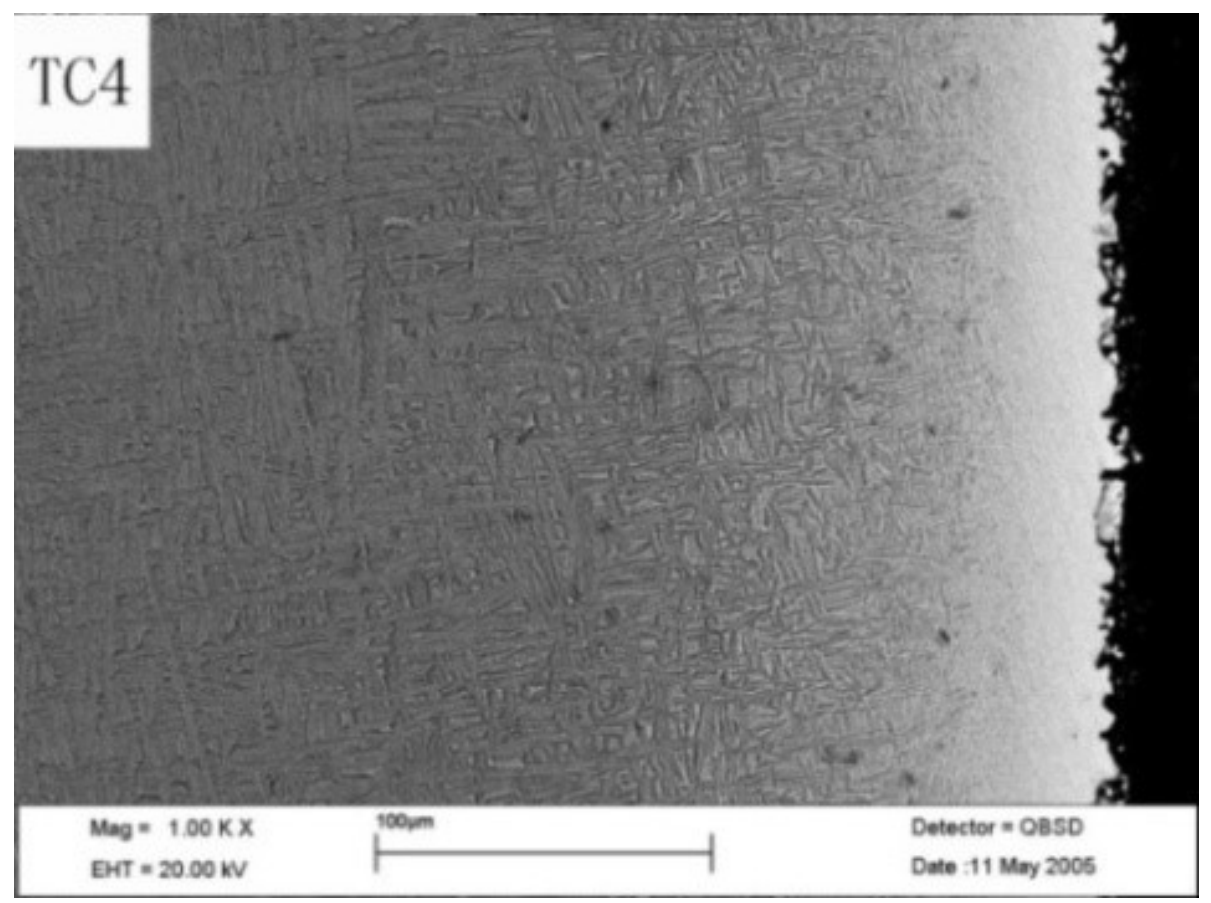

Figure 9. SEM photos of section of $\mathrm{Nb}$ modified layer on TC4

The surface alloy layer of Ti-Mo also has flame retardant property. Molybdenum, with a the body centered cubic lattice, can form continuous solid solution with $\beta$-Ti who has the same crystal lattice, and limited solid solution with a-Ti who has closepacking hexagonal lattice. Solubility of $\mathrm{Mo}$ in $\mathrm{a}-\mathrm{Ti}$ is very low, no more than $0.8 \%$. The formation of $\mathrm{Ti}$ and Mo is substitutional solid solution, with a small lattice distortion; therefore, the Ti-Mo substitutional solid solution with high content of Mo not only has high strength, but also maintains high plasticity. The composition distribution of diffusion layer on TC4 substrate is shown in 
Figure 10. The outmost surface is $3 \mu \mathrm{m}$ deposition layer, with content of Mo for $100 \%$. In the layer $3 \sim 30 \mu \mathrm{m}$ from surface, Mo element shows a gradient distribution. The thickness of the layer is about $40 \mu \mathrm{m}$.

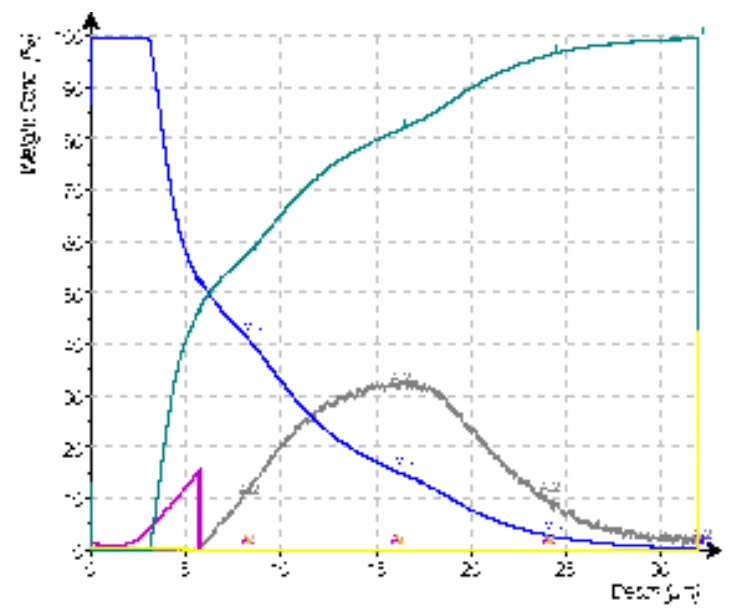

Figure 10. The distribution of Mo in alloy layer on TC4

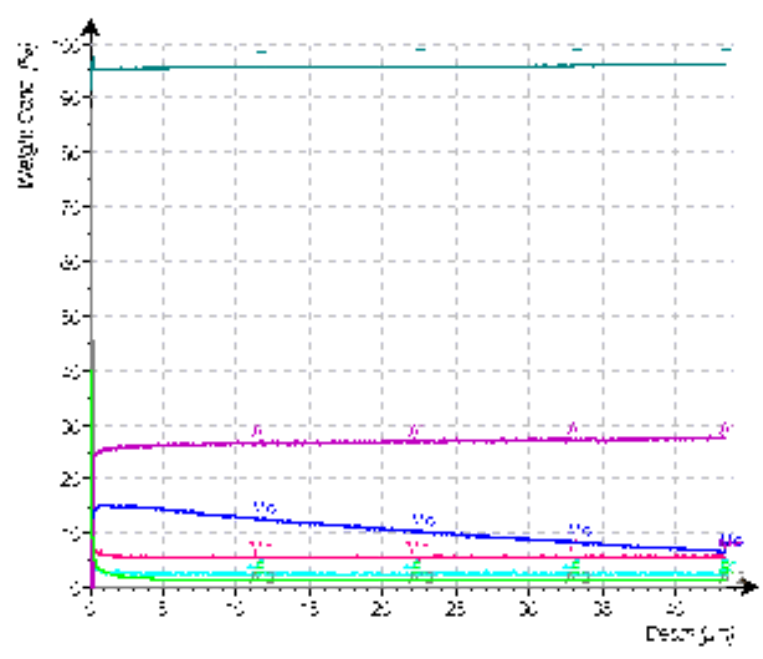

Figure 11. The distribution of Mo in alloy layer on TC11

The composition distribution of diffusion layer on TC11 titanium alloy after surface plasma Mo diffusion is shown in Figure 11. Mo content at outmost surface is $1.5 \%$, and remains above $0.8 \%$ at $30 \mu \mathrm{m}$ from the surface, with a low gradient concentration. The thickness of the layer is about $100 \mu \mathrm{m}$.

A series of surface flame retardant alloy coatings including Ti-Cu, Ti-Mo, Ti-Cr, Ti-Nb, etc., have been successfully prepared on the surface of titanium alloy by adopting the double glow plasma surface alloying technology, shows significant advantages compared with the flame retardant titanium alloy.

\subsection{Surface corrosion resistant titanium alloy $[9,10]$}

A typical structure of Ti-Pd layer on the titanium surface is shown in Figure 12. The thickness of Ti-Pd alloy layer is generally greater than $50 \mu \mathrm{m}$, which is dense and forms a "canine" shaped interface with titanium substrate. TiPd2, TiPd3, Ti2Pd, and still a$\mathrm{Ti}$ are formed in the Ti-Pd alloy layer. The content distribution of Pd in alloy layers is shown in Figure 13. The content of Pd varies greatly in different layers. However, in each layer the content of Pd is linearly decreasing. 


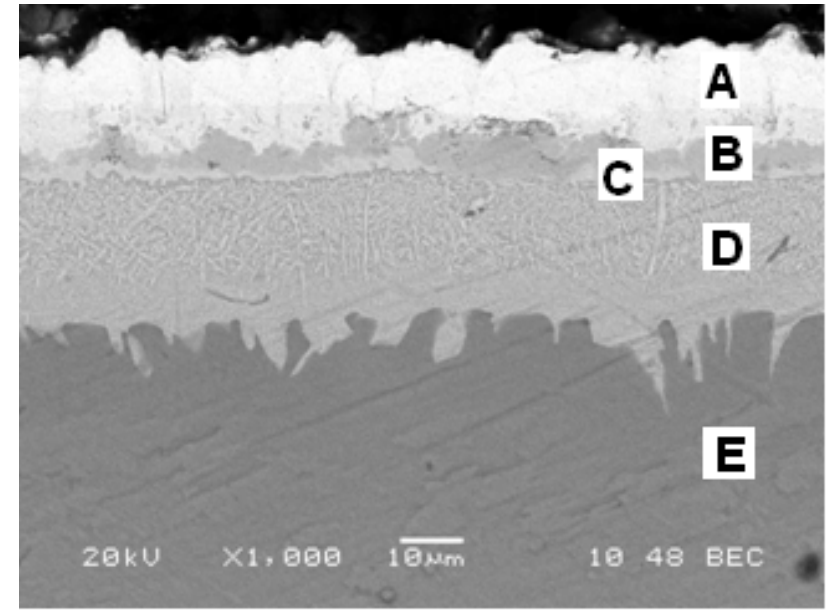

Figure 12. The BEC photo of section of Ti-Pd layer

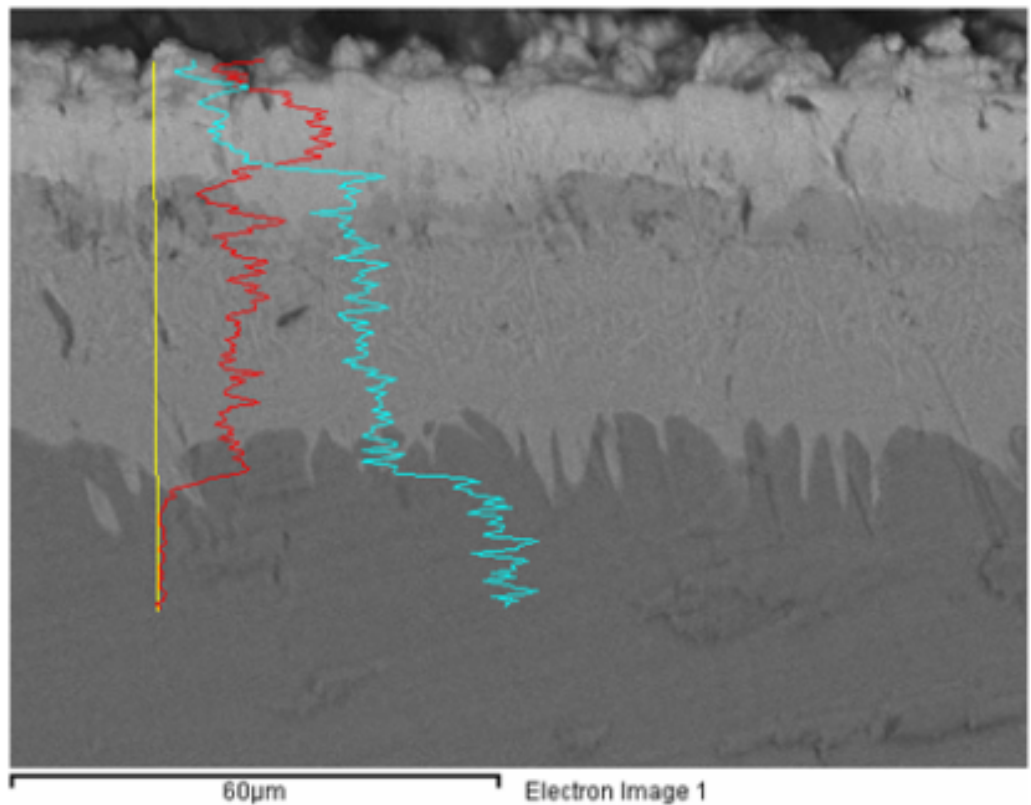

Figure 13. The energy line of scanning position

Ti-Pd alloy layer on titanium surface has excellent corrosion resistance. The corrosion rate of Ti-Pd alloy layer on the titanium surface is only $0.682 \mathrm{~mm} / \mathrm{a}$ in the $25^{\circ} \mathrm{C}$ water solution of $\mathrm{H}_{2} \mathrm{SO}_{4}, 1 / 6$ of that of Ti-Pd alloy; in the $25^{\circ} \mathrm{C}$ water solution of $30 \% \mathrm{HCl}$, the corrosion rate of the Ti-Pd alloy layer is only $0.004 \mathrm{~mm} / \mathrm{a}, 1 / 8$ of that of Ti- $0.2 \mathrm{Pd}$ alloy.

\subsection{Mo-N-Ti surface wear resistant alloy [11-13]}

From the X-ray diffraction diagram of sample is shown in Figure 14. The modified layer of molybdenitriding and modified layer of nitriding after molybdenizing both have $\mathrm{Mo}_{2} \mathrm{~N}, \mathrm{MoN}$ and Mo phases. Molybdenitriding layer on the surface of Ti6Al4V consists more $\mathrm{Mo}_{2} \mathrm{~N}$ and only a small amount of $\mathrm{MoN}$ and Mo. Nitriding after molybdenizing layer mainly formed by MoN, together with small amount of $\mathrm{Mo}_{2} \mathrm{~N}$. Both the layers have no matrix elements, which means all of the outmost layers are modified layers of Mo. The hardness of Mo-N modified layer is $1804 \mathrm{HV}$, the hardness of nitriding after molybdenizing layer is 1681HV. 


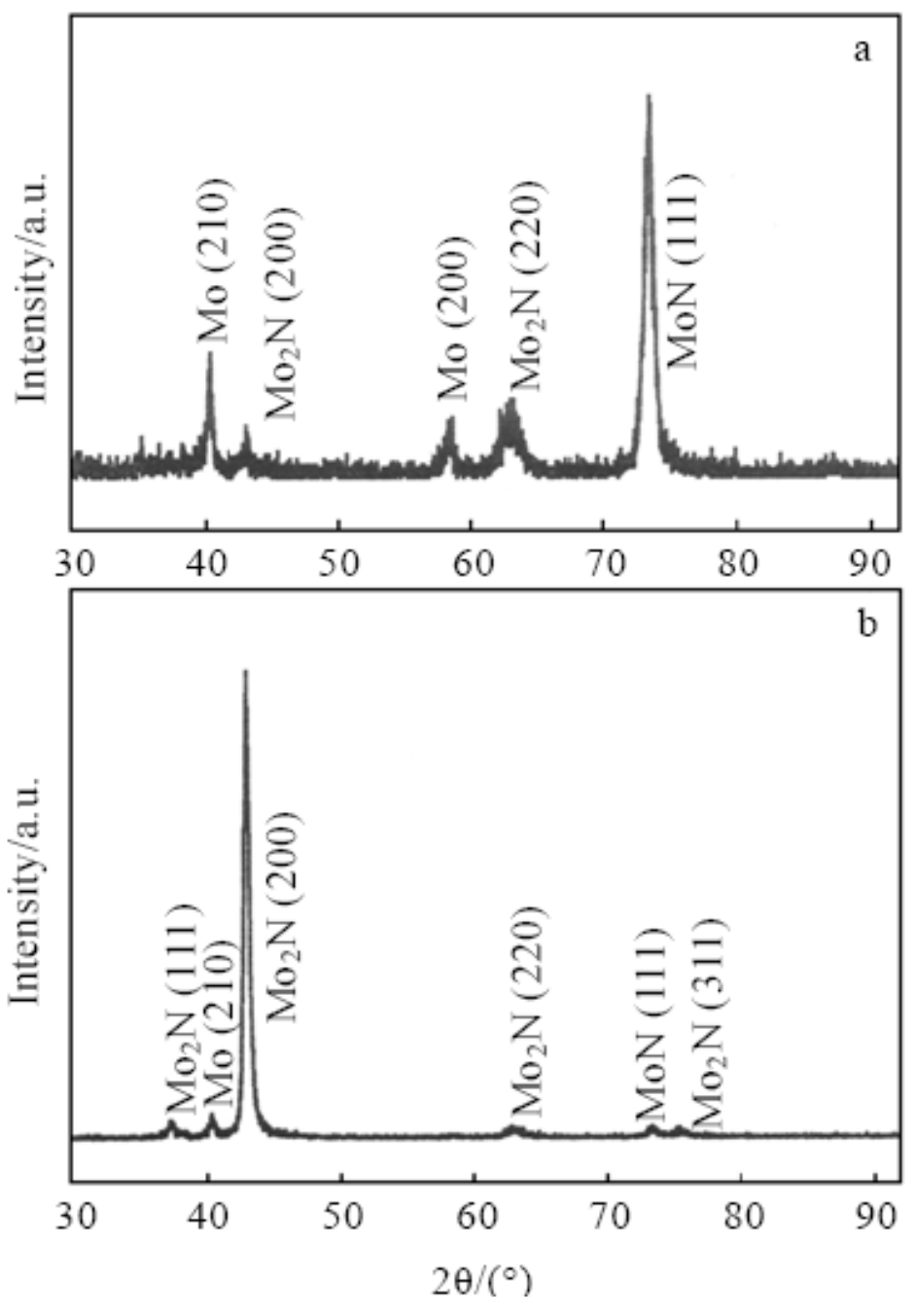

Figure 14. XRD analysis results of alloy layer(a) $\mathrm{N}$ after Mo ; (b) Mo-N

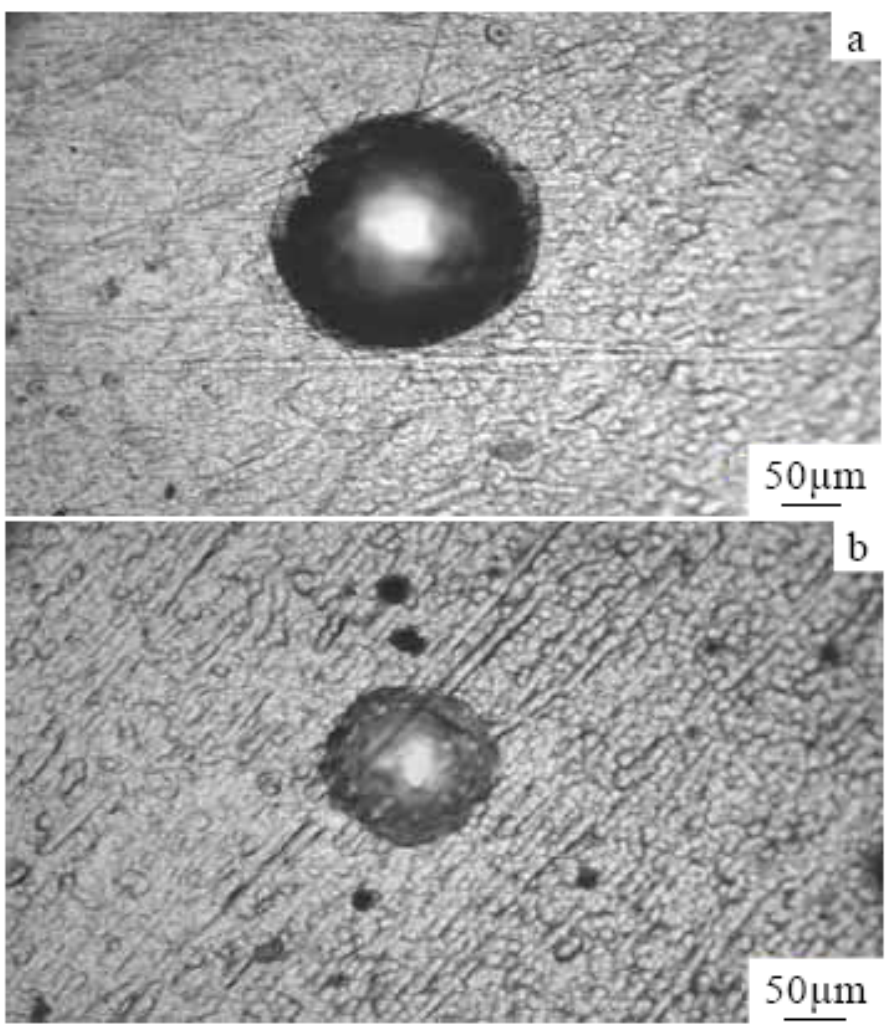


Figure 15. Indentation morphology of specimen at critical load(a) N after Mo ; (b) Mo-N

Figure 15 shows the indentation morphology of two different critical loads. There is a small amount of redial cracks on the edge of the alloy layer, and there is no peeling off, which indicates that the combination of the alloy layer and the substrate is firm, with no interface weakening phenomenon. The Pc value of the nitriding after molybdenizing layer is $180 \mathrm{~N}$, which is substantially higher than $120 \mathrm{~N}$ of the molybdenitriding layer.

With the running-in distance of $200 \mathrm{~m}$, compared with the original Ti6Al4V sample, the wear rate of Mo-N modified sample decreased by 405 times, and the wear rate of $\mathrm{N}$ after Mo modified sample decreased by 1081times.

\subsection{Non-hydrogen carburizing technology on titanium surface}

\subsubsection{Hydrogen embrittlement of titanium materials}

Carburizing technology is a traditional surface chemical heat treatment technology, and has been widely adopted in iron and steel industry. The existing carburizing technologies includes solid carburizing, gas carburizing, ion carburizing and so on. It is well known that hydrogen is involved in those carburizing technologies. Titanium is an active metal with strong affinity to hydrogen, especially at high temperature, it will absorb hydrogen, so the hydrides are generated. When the accumulation of hydrides reaches a certain level, the impact toughness and extensibility of titanium reduce rapidly, hydrogen embrittlement phenomenon occurs ${ }^{[13]}$.

\subsubsection{The structure of non-hydrogen carburizing technology on titanium surface ${ }^{[14]}$}

Figure 16 shows the surface X-ray diffraction pattern of industrial pure titanium after double glow plasma non-hydrogen carburizing. High hardness phase TiC is formed in the diffusion layer, as well as some free-state carbon elements. The formation of TiC phase will undoubtly increases the hardness of the material, reduces friction coefficient and improves the wear resistance of the material. The free-state carbon elements will mainly exist on the surface of the sample, which will play a role in reducing the friction, as well as improving wear resistance.

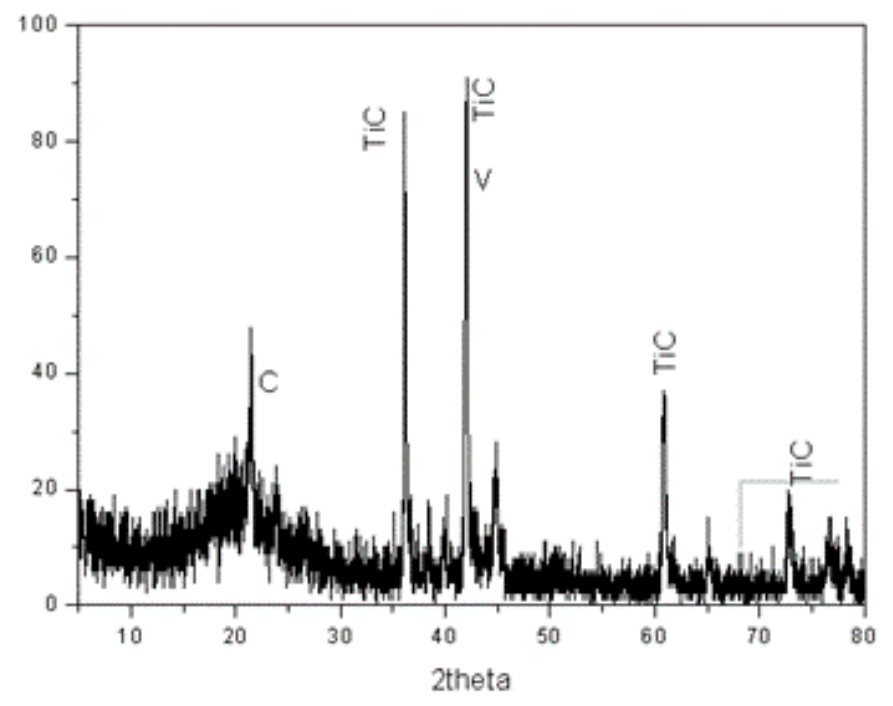

Figure 16. The X-ray diffraction spectrum of pure titanium after non-hydrogen carburizing

The surface layer of the carburized layer on titanium alloy formed by non-hydrogen carburizing is composed of TiC and a small amount of non-carburized C. Shown in Figure17, in the carburizing layer, the grain is fine due to the infiltration of C. From the surface to the matrix direction, the grain size increases with the decrease of C element, and there is fine and uniform needlelike TiC in the layer. Figure 18 shows the relationship between the thickness of the carburizing layer and the heat-retaining time at the workpiece temperature. The thickness of the carburizing layer is increasing with the prolonging of the heat-retaining time. 


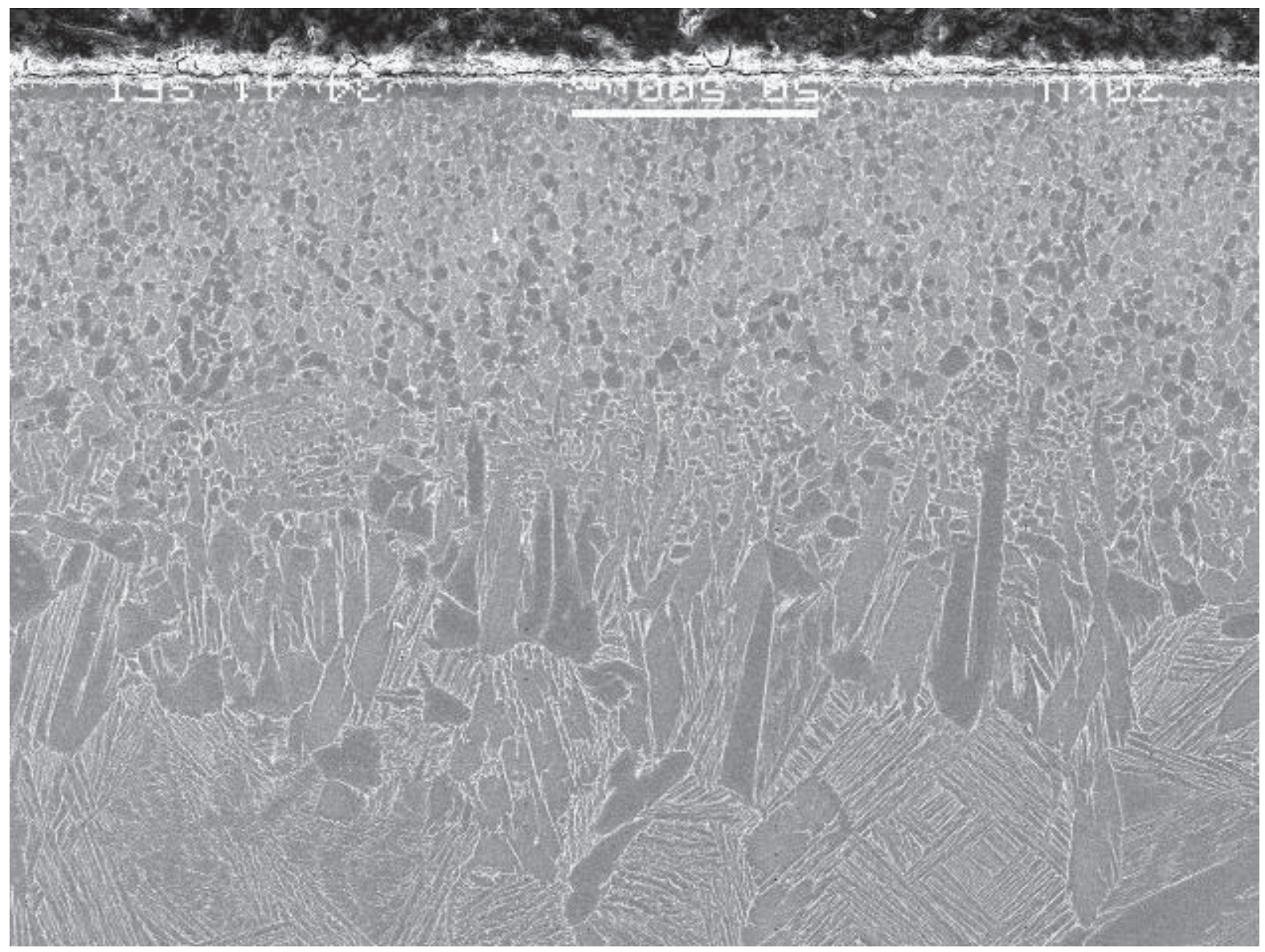

Figure 17. The SEM photo of non-hydrogen carburizing layer

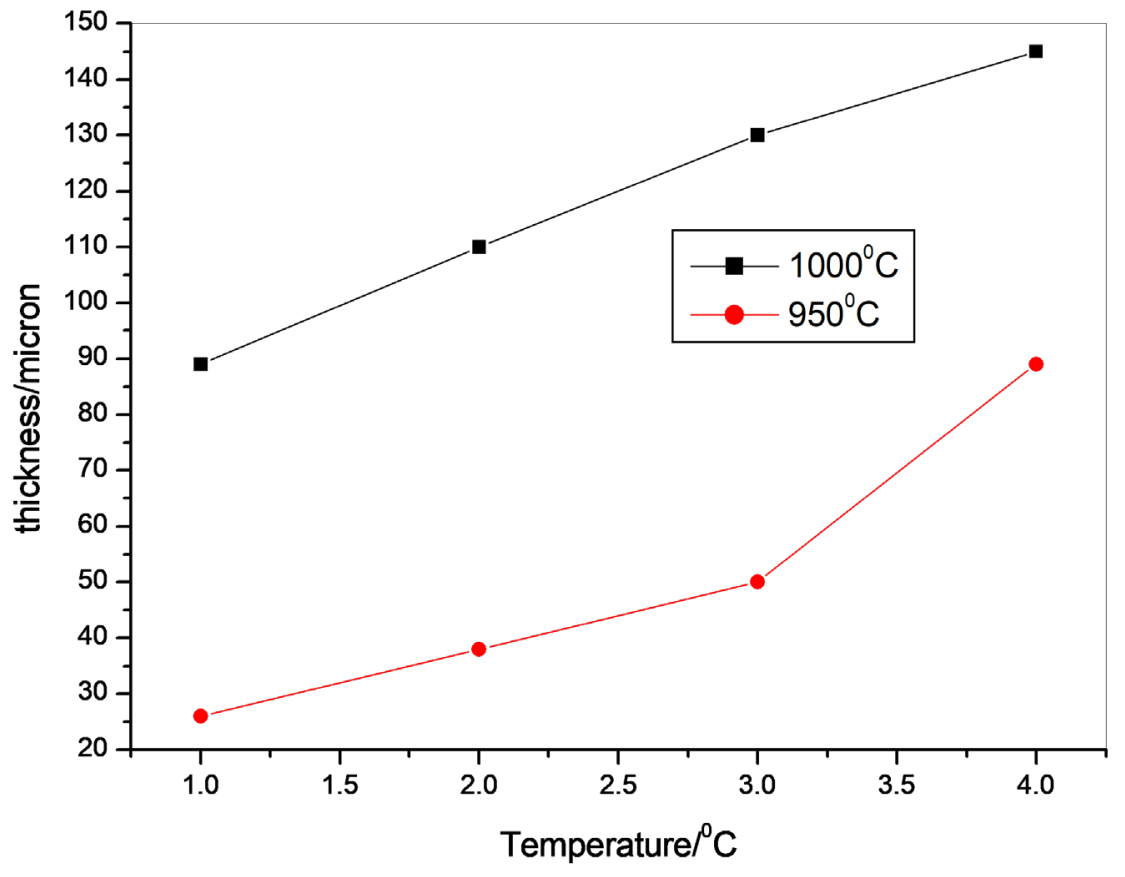

Figure 18. The relationship between the depth of carburizing layer and the heat-retaining time

Figure 19 shows the $\mathrm{Ti}$ and $\mathrm{C}$ element distribution of the carburizing layer on the industrial pure titanium. Ti and $\mathrm{C}$ showed a gradient distribution from the outside to the inside of the layer. Ti showed a gradient ascent, while $\mathrm{C}$ a gradient descent, especially in the range of $0 \sim 2 \mu \mathrm{m}$, Ti increased rapidly, while C decreased rapidly. C decreased from $95.71 \%$ to $6.583 \%$, while $\mathrm{Ti}$ 
increased from $3.218 \%$ to $93.35 \%$. Then the decrease became slower afterward, until $16.577 \mu \mathrm{m}$ the $\mathrm{C}$ content is still $0.204 \%$, higher than that of substrate.

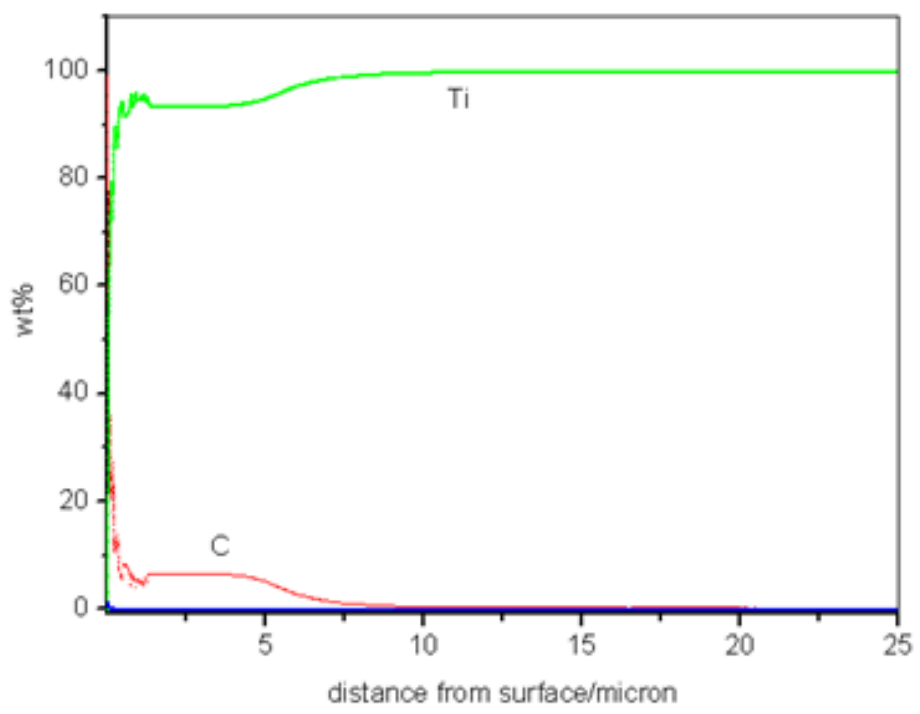

Figure 19. The composition of carburizing layer on pure titanium after $960^{\circ} \mathrm{C} \times 3 \mathrm{~h}$ non-hydrogen carburizing

\subsubsection{The properties of non-hydrogen carburized layer on titanium surface ${ }^{[15-18]}$}

Figure 20 shows the hardness curve of non-hydrogen carburized pure titanium. The hardness is a parabolic-shaped curve, with the maximum value at the surface. The hardness decreases rapidly within the $25 \mu \mathrm{m}$ from the surface, and afterward, there is a stable decreasing zone. It is because TiC prevents the diffusion of $\mathrm{C}$ to a certain degree. The formation of TiC on the surface will block the further inward diffusion of C, which decreases the surface hardness. Industrial pure titanium, TC4, TC6 and TC11 all exhibit the above hardness distribution rules, only with different the absolute hardness of the non-hydrogen carburized layer due to differences of element contents in substrate alloys.

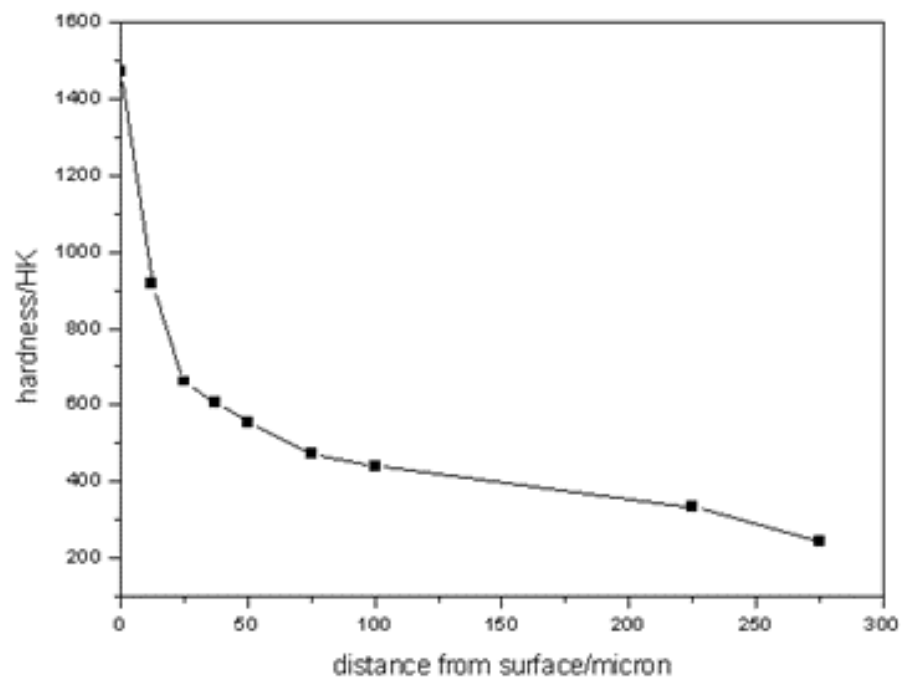

Figure 20. The hardness curve of pure titanium after non-hydrogen carburizing

Studies show that, after a brief running-in stage, when carburized TC4 grinding with GCr15 under dry friction condition entered the normal stable wear stage, the friction coefficient of carburized TC4 tended stable, at around 0.23 , which is about $30 \%$ of that of the untreated sample. The wear rates of carburized samples are about $2 \%-7 \%$ of that of the untreated one, which shows that wear rate can be reduced by carburizing.

The carburized samples and pure titanium samples were soaked for a week (168h) under different concentrations of sulfuric acid and hydrochloric acid at room temperature. The corrosion rates are shown in Figure 21 and 22. When the concentration is 
higher than $10 \%$, the corrosion rates of the carburized samples are substantially lower than those of the untreated samples. The corrosion rate is at a low level, about $0.0599 \mathrm{~mm} / \mathrm{a}$. In the $10 \% \sim 80 \% \mathrm{H}_{2} \mathrm{SO}_{4}$ solution, the carburized samples also show decent corrosion resistance, the corrosion rates maintain at $0.002-0.0820 \mathrm{~mm} / \mathrm{a}$. The improvement of corrosion resistance lays a theoretical foundation for the application of titanium in chemical engineering.

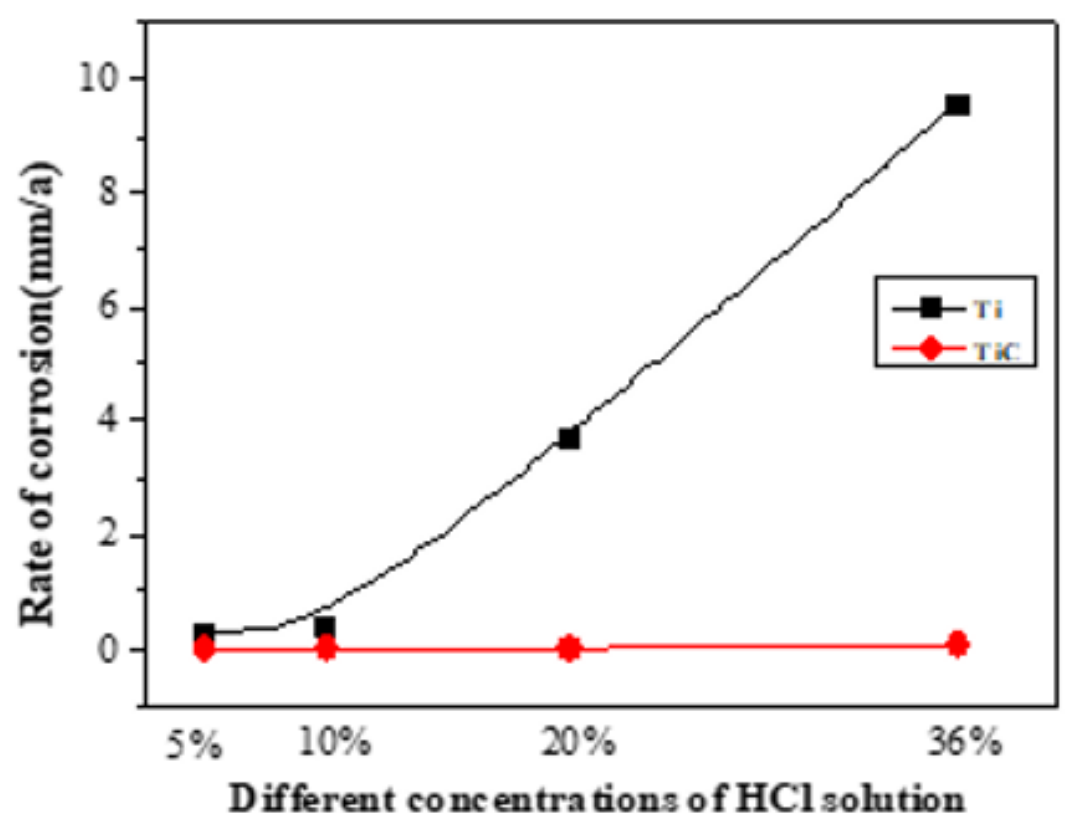

$\mathrm{HCl}(\mathrm{wt} \%)$

Figure 21. Comparison of corrosion rate of the samples before and after carburizing in $\mathrm{HCl}$ solution

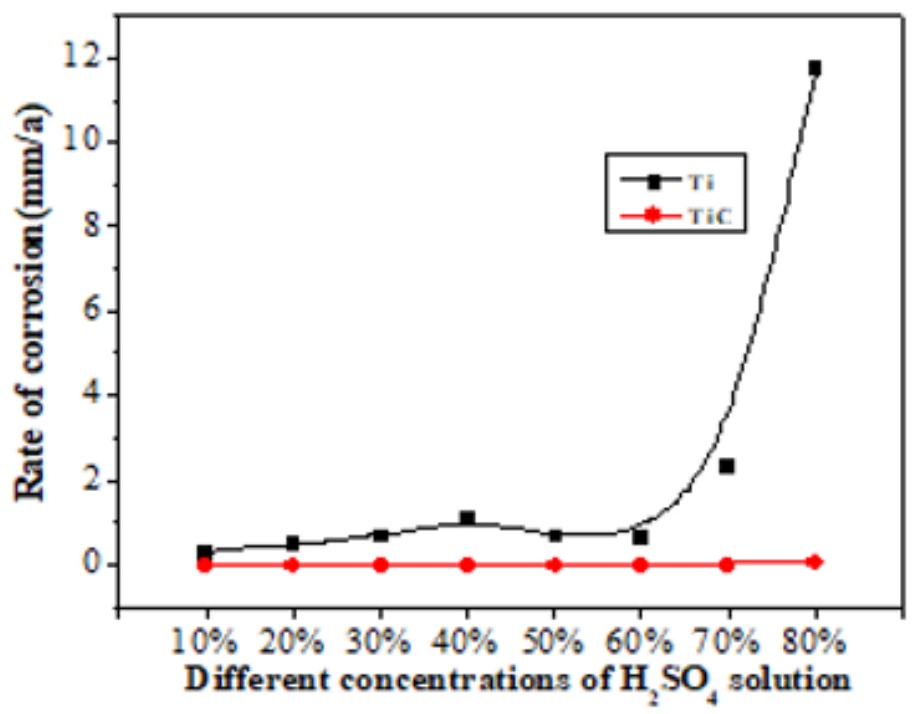

$\mathrm{H}_{2} \mathrm{SO}_{4}(\mathrm{wt} \%)$

Figure 22. Comparison of corrosion rate of the samples before and after carburizing in $\mathrm{H} 2 \mathrm{SO} 4$ solution

\section{Conclusion and Prospect}

1. The study of engineering application technology of double glow plasma surface metallurgy wear resistant TiC titanium alloy needs to go deeper and further; solve the relationship between the structure size precision of the parts and the wear resistance of the alloying layer in the project; produce the titanium alloy parts with high performance, high precision, to meet the more extensive engineering and technical requirements. 
2. Based on the successful preparation of Ti-Pd surface alloy layer, continue to carry out the further study of plasma surface metallurgy processing fundamental theories for reducing the Pd content in Ti-Pd alloy layer, and the application engineering technology of corrosion resistant equipment materials for chemical industry.

3. Carry out the research of the flame retardant performance evaluation method and test and so on for the prepared surface flame retardant titanium alloy, although there is no accurate evaluation method by now.

4. By using the double glow plasma surface metallurgy technology, carry out the study on the functional coating of electric, magnetic, acoustic, wave and other aspects on the surface of titanium alloy, and develop new types of titanium alloy.

\section{Reference}

[1]. K.G. Budinski, Tribological properties of titanium alloys [J]. Wear. 151(1991) 203-217.

[2]. Li Zhengxian, Zhou Lian, Xu Zhong, et al. Surface plasma metallurgy technologies of titanium, Rare Metal Letters [J]. 23(2004) 2: $1-3$.

[3]. Chen Guang. Harm and Prevention measures of high pressure compressor titanium combustion. International Aviation. 1 (1995) 40-42.

[4]. Wang Jinyou. Development of anti burning titanium alloy in Russia. Aeronautical Science \& Technology. 3 (1995) 38-40.

[5]. Zhang Pingze, Xu Zhong, Zhang Gaohui, He Zhiyong. Preparation of double glow plasma surface metallurgy treated Ti-Cu burn-resistant alloy. The Chinese Journal of Nonferrous Metals. 15 (2005) 1: 110-115.

[6]. Zhang Pingze, Xu Zhong, Zhang Gaohui, He Zhiyong. Study of surface burn-resistant Ti-Cu titanium alloy. Rare Metal Material and Engineering. 34 (2005)1: 162-165.

[7]. Zhang Pingze, Li Zhonghou, He Zhiyong. Surface chromizing of Ti-6Al-4V by double glow plasma surface alloying technology. Ordnance Material Science and Engineering. 28 (2005)1: 18-25.

[8]. Wenbo Wang, Zhong Xu, Zhiyong He, et al. Study on double-glow plasma niobium surface alloying of pure titanium. Vacuum. 81(2007)937-942.

[9]. Wang Zhenxia, Wang Wenbo, He Zhiyong et al. Study of plasma niobium surface alloying on titanium (TA2) and Titanium alloys (TC4). Hot Working Technology. 9 (2005) 1-2.

[10]. Li Zhengxian, Du jihong, et al. Performances of Ti-Pd coating on titanium surface prepared by double glow plasma technology [J]. Rare Metal Materials and Engineering. 35 (2006) 8: 1239-1243.

[11]. Zhang Zeping, Xu Zhong, Zhang Gaohui. Double glow plasma surface molybdenizing of pure Ti nad Ti-6Al-4V. Journal of Nanjing University of Aeronautics \& astronautics. 37(2005) 5:582-586.

[12]. Qin Yanmei, et al. Study on corrosion behavior of plasma Mo-N modified titanium in artificial blood solution. Physical Testing and Chemical Analysis Part A: Physical Testing. 41(2005)3: 117.

[13]. Hu Hongjuan, et al. Electrochemical behavior of Mo-N modified layer on pure titanium with plasma surface alloying technique. Rare Metals Letters. 24(2005)11:21.

[14]. Zhou Dehui, TanYun. Environmental hydrogen embrittlement of metal and its testing technology. National Defend Industry Press. 1998. 12, First Edition.

[15]. Zhang Gaohui, Pan Junde, He Zhiyong, et al. Double glow plasma hydrogen-free carburizing on commercial purity titanium. Journal of Wuhan University of Technology-Mater.Sci.Ed. 20(2005)4: 80.

[16]. Zhang G H, Pan J D, Xu Zhong, et al. Double glow plasma carburizing without hydrogen of titanium alloy [J]. Nonferrous Metal. 56(2004)1: 4-6.

[17]. Zhang Gaohui, He Zhiyong, et al. Mechanical and tribological properties of titanium alloys by double glow plasma hydrogenfree carbonitriding. Materi. Sci. Forum. 475-479(2005) 3951-3954. 
[18]. Ji Shouchang, Li Zhengxian, Wang Yanfeng The effect of Non-hydrogen carburizing on mechanical properties of TC4 titanium alloy [J]. Rare Metal Materials and Engineering, 10(2016)2734-2740. 